\title{
Aging, Myopia, and the Pay-As-You-Go Public Pension SYSTEMS OF THE G7: A BRIGHT FUtURE?
}

\author{
ROWENA A. PECCHENINO \\ Michigan State University \\ PATRICIA S. POLLARD \\ U.S. Department of the Treasury
}

\begin{abstract}
Public pension systems of the G7 countries were established in an era when contributors far outnumbered beneficiaries. Now, for each beneficiary there are fewer contributors, and this trend is projected to accelerate. To evaluate the prospects for these economies we develop an endogenous growth overlapping generations model. We analyze individuals' behavior when their expectations regarding longevity are rational or myopic, and examine whether policies exist that can offset any adverse effects of aging. We find that while perfectly anticipated aging is welfare improving, myopia worsens welfare, puts pension systems at risk, and cannot be easily remedied by public policy.

"Population aging is the single most consistent pressure on federal income security spending, as public pension spending continues its relentless upward climb."

\section{Douglas Young, former Canadian Minister of Human Resources Development}

\section{Introduction}

The public pension systems of the G7 countries were established in an era when the number of contributors to the pay-as-you-go schemes far outweighed the number of beneficiaries. Over the post-World War II period the systems have matured and the populations of the G7 countries have aged as longevity

Rowena A. Pecchenino, Department of Economics, Michigan State University, East Lansing, MI 48824-1038 (rowenap@msu.edu). Patricia S. Pollard, U.S. Department of the Treasury, Washington, DC 20220 (patricia.pollard@do.treas.gov).

The views expressed in this paper are solely those of the authors and do not necessarily reflect the views of the U.S. Department of the Treasury of the Federal Reserve System.

Received June 2002; Accepted November 2003.

(c) 2005 Blackwell Publishing, Inc.

Journal of Public Economic Theory, 7 (3), 2005, pp. 449-470. 
has risen and birth rates have fallen. Now, for each beneficiary there are fewer contributors, and this downward trend is projected to accelerate. To maintain benefit levels, tax rates and/or productivity growth will have to rise. Evaluating the future of the systems, individual contributors express grave doubts that they will receive as they did give (Saito 1998).

To evaluate the prospects for these economies we develop an overlapping generations model in which individuals face uncertainty over their longevity, growth is endogenously fueled by individuals' investments in physical capital, and individual and government investment in human capital. All retirees receive public pension benefits, funded in a pay-as-you-go manner. We analyze individuals' behavior and social welfare when expectations over length of life are rational or adaptive (myopic). Using simulations of our model in which parameter values are drawn from the individual economies of the G7, we examine for each of the economies and for each of the expectations assumptions whether policies exist that can offset any adverse effects of aging. Further, we examine how policies aimed at a specific target group, for example, the elderly or the young, affect current and future welfare of the economy as a whole.

Our model is similar in construct to Docquier and Michel (1999) and Kaganovich and Zilcha (1999), which also examine the effects of the public funding of pensions and education on economic growth. ${ }^{1}$ We, however, as in Glomm and Kaganovich (2003), take the constraints of the public pension system (benefits are determined as a replacement rate on wages, so benefits determine taxes) explicitly into account in our analysis. Thus we assume that the government, effectively, faces two budget constraints, a public pension constraint and an education constraint, rather than a unified constraint with the explicit tradeoff assumed (more for public pensions implies less for education). Kaganovich and Zilcha focus on the trade-off between education and public pension spending absent an aging population. Docquier and Michel incorporate population growth to model a transitory demographic shock, whereas we model a demographic transition. Our model differs from these and other studies, such as Auerbach et al. (1989) and Hviding and Mérette (1998), in that we incorporate uncertainty regarding length of life; thus allowing us to determine the importance of expectations regarding longevity.

Our model differs from previous studies of myopia and public pensions in that we are not attempting to determine the optimal structure of the public pensions given myopia, as in Feldstein (1985) and Hu (1996). Our work takes the current systems in the G7 countries as given, examines the effects of myopia on economic growth and welfare, and looks for policies to ameliorate those effects, if adverse.

Our findings suggest that perfectly anticipated population aging may be beneficial to the economy as a whole and does not pose a threat to the solvency

${ }^{1}$ For a review of the literature relating to public pensions and education, see Kaganovich and Zilcha (1999). 
of the public pension system. Greater longevity induces higher rates of saving for retirement, whereas declining population growth increases human capital expenditures per child. These effects offset the negative effects of the higher tax rate that is necessary to maintain a given stream of public pension benefits. As a result the growth rate of output per worker rises, and with it, welfare. ${ }^{2}$ Nonetheless, aggregate saving typically declines resulting in a reduction in the growth rate of aggregate output. ${ }^{3}$

When agents are myopic, both social welfare and growth are adversely affected because taxes rise but the positive longevity effect on saving is absent. Any policy targeted at retirees, for example, to maintain their standard of living over their individually unanticipated longer lives, will exacerbate the problem because taxes to fund such a program will further reduce saving. Policies directed at the very young, such as higher expenditures on public education, may generate positive growth effects but will not benefit the initial generation of retirees, as the effects are felt only with a lag. For such policies to offset the effects of both myopia and aging, they must be put in place prior to the onset of aging. Thus, myopia, not aging per se, is the biggest threat to public pension system viability.

\section{The Model}

The model developed below is an application of Pecchenino and Pollard (2002) and is similar to that of Kaganovich and Zilcha (1999). ${ }^{4}$ There is an infinitely lived economy composed of finitely lived individuals, firms, and a government. A new generation is born at the beginning of each period and lives for at most three periods: youth, working age, and retirement. At each period $t, N(t)$ identical agents of generation $t$ enter the workforce. The working-age population grows at the rate $n(t)$.

\subsection{Consumers}

At date $t$, agents in the first period of their lives, the young, neither consume nor produce. They are endowed with one unit of time that they combine inelastically with resources provided by their parents, $e(t)$, and the government, $e^{g}(t)$, to develop their human capital, $h_{t+1}(t+1)$. Agents in the second period of their lives, the workers, supply their effective labor, the product of their one unit of time and their human capital developed in youth, inelastically to firms. In return, they receive wage income, $w(t) h_{t}(t)$ from which they pay a pension tax, $\tau(t)$, and a school tax, $\omega(t)$. They also may receive bequests, $B(t)$, from

\footnotetext{
${ }^{2}$ In contrast, Turner et al. (1998) find that aging reduces the growth rate of GNP per capita. ${ }^{3}$ Most studies of aging focus on aggregate saving and find that aging reduces the saving rate. See, for example, Auerbach et al. (1989), Hviding and Mérette (1998), Masson and Tryon (1990), and Roseveare et al. (1996).

${ }^{4}$ Derivations for this model follow those for Pecchenino and Pollard (2002). We direct the reader there for a more detailed discussion of the underlying assumptions, etc.
} 
their parents, which are tax free. Their disposable income is divided between funding their children's human capital development, $e(t)$, their current consumption, $c_{t}(t)$, and saving, $s(t)$, for their consumption when retired, $c_{t}(t+$ $1)$. Agents in the final period of their lives, the retirees, supply their savings, $s(t-1)$, inelastically to firms and consume their public pension benefits, $T(t)$, and the return to their savings, $(1+\rho(t)) s(t-1)$. With probability $p(t-1)$ an agent who worked during period $t-1$ will live throughout the retirement period, and with probability $(1-p(t-1))$ the agent will die at the onset of retirement. Agents may form expectations of living into retirement rationally or adaptively (myopically). Rational expectations mean that working-age agents know their probability of dying at the onset of retirement; they have perfect foresight. Adaptive expectations means that a working-age individual assumes that his life expectancy is a convex combination of the actuarial forecast, $p(t)$, the life expectancy of his parents' generation, $p(t-1)$, and possibly the life expectancy of his grandparents' generation, $p(t-2)$. Let $\hat{p}(t)$ be the member of generation t's assessment of life expectancy. If an agent dies at the onset of retirement, his saving is bequeathed to the members of generation $t, B(t)=[(1+\rho(t)) /(1+n(t))] s(t-1)$.

Personal saving in this model is the equivalent of the sum of the occupational "second pillar" and the personal "third pillar" of retirement security. This is because, in the context of this model, a defined-contribution occupational pension plan will earn the same return as private saving. Thus, as long as the defined contribution is less than or equal to what agents would choose to save absent the program, combining these two pillars has no affect on the behavior of the model.

For tractability, let the preferences of a representative worker at time $t$ be represented by

$$
U_{t}=\ln c_{t}(t)+\hat{p}(t) \ln c_{t}(t+1)+\delta(1+n(t+1)) \ln h_{t+1}(t+1) .
$$

Parents get utility from consumption and from educating their children; the value of this education is summarized by the child's human capital. This utility is derived from an altruistic link between parent and child rather than any personal return they may reap from their investment or other strategic motive (see Cremer et al. 1992). This inter vivos bequest motive encompasses the lifetime bequest motive. Since agents do not know when they will die, additional unintentional bequests may be forthcoming.

Parental and government investments are both essential for human capital formation. If a parent invests $e(t)$ and the government invests $e^{g}(t)$, then the child's human capital will be

$$
h_{t+1}(t+1)=e_{t}(t)^{\theta_{1}(t)} e^{g}(t)^{\theta_{2}(t)}
$$

where the parameters $\theta_{1}(t)$ and $\theta_{2}(t)$ measure the elasticity of parental and government expenditures on human capital, respectively. This modeling of educational attainment follows Hanushek's (1992) achievement function. Parental, $e(t)$, and governmental expenditures, $e^{g}(t)$, and the efficiency of 
those expenditures, $\theta_{1}(t)$ and $\theta_{2}(t)$, matter for human capital development. The utility a parent receives from his dependent children's human capital is $\delta(1+n(t+1)) \ln h_{t+1}(t+1) ; \delta$ is the discount factor.

The representative agent takes as given his human capital, wages, return on saving, the pension and school tax rates, public pension benefits, bequests, and government expenditures on education. The agent then chooses saving and education expenditures to maximize lifetime utility as given by Equation (1) subject to (2) and the following budget constraints

$$
\begin{aligned}
c_{t}(t)= & w(t) h_{t}(t)(1-\tau(t)-\omega(t))-s(t) \\
& -(1+n(t+1)) e(t)+(1-p(t-1)) B(t) \\
c_{t}(t+1)= & (1+\rho(t+1)) s(t)+T(t+1),
\end{aligned}
$$

where constraint (3) encompasses the assumption that bequests are allocated equally across all members of a generation so that the bequest-dependent wealth distribution is uniform, as in Hubbard and Judd (1987). This assumption allows us to conduct a representative agent analysis, and restricts uncertainty to the timing of death alone.

The first-order conditions for this problem, with respect to $s(t)$ and $e(t)$, respectively, are

$$
-\frac{1}{c_{t}(t)}+\frac{\hat{p}(t)(1+\rho(t+1))}{c_{t}(t+1)}=0
$$

and

$$
-\frac{1}{c_{t}(t)}+\frac{\delta \theta_{1}}{e(t)}=0
$$

\subsection{Firms}

The firms are perfectly competitive profit maximizers that produce output using the production function $Y(t)=A(t) K(t)^{\alpha} H(t)^{1-\alpha}, \alpha \in(0,1)$. The value $K(t)$ is the capital stock at $t$, which depreciates fully in the production process. The value $H(t)$ is the effective labor input at $t, H(t)=N(t) h_{t}(t)$, where $N(t)$ is labor hours. The value $A(t)>0$ is a productivity scalar. The production function can be written in intensive form

$$
y(t)=A(t) h_{t}(t)^{1-\alpha} k(t)^{\alpha},
$$

where $y(t)$ is output per worker and $k(t)$ is the capital labor ratio.

Firms take the wage, $w(t)$, and rental rate, $R(t)$, as given. They hire effective labor and capital up to the point where their marginal products equal their factor prices: 


$$
\begin{aligned}
(1-\alpha) A(t) h_{t}(t)^{-\alpha} k(t)^{\alpha} & =w(t) \\
\alpha A(t) h_{t}(t)^{1-\alpha} k(t)^{\alpha-1} & =R(t) .
\end{aligned}
$$

\subsection{The Government}

The government administers the public pension program and funds education. It levies proportional income taxes, $\tau(t)$ and $\omega(t)$, on the workers to finance pension and education expenditures, respectively. Public pension benefits are specified as a replacement rate on the wages of current workers. Thus, $T(t)=\xi(t-1) w(t) h_{t}(t)$, where $T(t)$ are the transfers to the retired at date $t$ and $\xi(t-1)$ is the replacement rate for retirees in period $t$, which is set in period $t-1$. The tax rate, $\tau(t)$, adjusts to ensure that public pension benefits equal tax revenues

$$
\frac{p(t-1)}{1+n(t)} T(t)=\frac{p(t-1) \xi(t-1)}{1+n(t)} w(t) h_{t}(t)=\tau(t) w(t) h_{t}(t) .
$$

Solving Equation (10) for $\tau(t)$ yields

$$
\tau(t)=\frac{p(t-1) \xi(t-1)}{1+n(t)} .
$$

Similarly, total government spending on education must equal total school tax revenues

$$
e^{g}(t)=\frac{\omega(t)}{1+n(t+1)} w(t) h_{t}(t) .
$$

\subsection{The Goods Market}

The goods market clears when the demand for goods equals the supply of goods:

$$
\begin{aligned}
& c_{t}(t)+\frac{p(t-1)}{1+n(t)} c_{t-1}(t)+s(t)+(1+n(t)) e(t)+(1+n(t)) e^{g}(t) \\
& =w(t) h_{t}(t)+R(t) k(t) .
\end{aligned}
$$

Substituting Equations (3), (4), (8), (9), (11), and (12) into (13), and making use of the fact that by arbitrage the return on capital must equal the return on saving,

$$
R(t)=1+\rho(t)
$$

yields

$$
s(t-1)=(1+n(t)) k(t) .
$$




\section{Equilibrium}

Definition 1: A competitive equilibrium for this economy is a sequence of prices and taxes $\{w(t), \rho(t), \tau(t), \omega(t)\}_{t=0}^{\infty}$, a sequence of allocations $\left\{c_{t}(t), c_{t}(t+1)\right\}_{t=0}^{\infty}$, and a sequence of human and physical capital stocks, $\left\{h_{t}(t), k(t)\right\}_{t=0}^{\infty}, k(0), h_{0}(0)>0$ given, such that given agents' expectations regarding longevity, and given these prices, allocations, and capital stocks, agents' utility is maximized, firms' profits are maximized, the government budget constraints are satisfied, and markets clear.

Substituting Equations (2)-(4), (8), (9), (11), (12), (14), and (15) into the first-order conditions given by Equations (5) and (6) results in the following set of difference equations in $k(t+1), e(t)$ and predetermined variables.

$$
\frac{\hat{p}(t)}{\left(1+n(t+1)+\frac{(1-\alpha) \xi(t)}{\alpha}\right) k(t+1)}-\frac{1}{\Lambda}=0
$$

and

$$
\frac{\delta \theta_{1}}{e(t)}-\frac{1}{\Lambda}=0
$$

where

$$
\begin{aligned}
\Lambda= & A(t)\left[\left(1-\frac{p(t-1) \xi(t-1)}{1+n(t)}-\omega(t)\right)(1-\alpha)+[1-p(t-1)] \alpha\right] \\
& \times e(t-1)^{\theta_{1}(t-1)(1-\alpha)} e^{g}(t-1)^{\theta_{2}(t-1)(1-\alpha)} k(t)^{\alpha} \\
& -[1+n(t+1)][e(t)+k(t+1)] .
\end{aligned}
$$

\section{The Analytics of Growth}

The following results are for the balanced growth specification of the model. Similar results hold for the steady-state model specification. All proofs are available from the authors on request.

PROPOSITION 1: Assume all parameter values are time independent, so $x(t)=x$ for all $t$ and for all parameters $x$. Then, economies with higher school taxes, $\omega$, will have higher growth rates if $\hat{\omega}>\omega$, where $\hat{\omega}=\theta_{2}[(1-p \xi /(1+n))(1-\alpha)+$ $(1-p) \alpha]$.

The school tax rate, $\omega$, represents the marginal cost of public education while the marginal benefit to the taxpayer, $\hat{\omega}$,is the marginal increase in income during one's working years, discounted by the marginal efficiency of the government's educational input, $\theta_{2}$. If $\hat{\omega}>\omega$, agents receive a positive income effect from an increase in the school tax rate, leading to increases in saving and investment in one's children's human capital. If $\hat{\omega}<\omega$, both 
saving and human capital investment fall. Thus, as Hanushek and Kim (1995) suggest, the economic benefits from education are higher the higher is the quality of the education, here measured by $\theta_{2}$.

If the economy is not on a balanced growth path then increases in the school tax from a suboptimal level toward a growth-maximizing level can have growth-increasing effects if the positive human capital effect tomorrow exceeds the negative physical capital effect today.

The following two propositions examine how economic growth is affected by changes in the two demographic parameters: expected longevity, $\hat{p}$, and the population growth rate, $n$. A rise in $\hat{p}$ affects growth through three channels. The expectation of a longer life increases saving for retirement (longevity effect). A longer lifespan reduces bequests (bequest effect) and also increases the tax rate required to fund public pension benefits (public pension effect), as shown in Equation (11). The first effect raises the economic growth rate while the latter two lower it.

A decrease in $n$ also has bequest and public pension effects. A decline in $n$ results in a rise in bequests received by each worker but raises the pension tax rate, a shown in Equation (11). A fall in the population growth rate raises educational expenditures per child (the education effect) and raises saving per worker (family size effect). All but the public pension effect raise the growth rate of the economy.

PROPOSITION 2: Economies in which expected longevity, $\hat{p}$, is higher have higher growth rates if the longevity effect dominates the bequest and public pension tax effects.

If agents expect to live longer, then, all else equal (including the age of retirement), they consume a higher proportion of their saving and leave less to their children. This negative bequest effect reduces expected income for working-age agents, reducing saving. Since pension taxes increase as longevity rises, income while working falls, compounding the negative bequest effect. The tax effect would be greater if labor supply were elastic, as some agents would choose to work less in response to the higher taxes. On the other hand workers expecting a longer lifespan increase their saving. If the longevity effect is dominant, physical capital accumulation and the equilibrium growth rate will rise.

When the increase in longevity is unexpected only the negative bequest and public pension effects remain. For example, suppose at date $t$ agents plan for the future expecting an unchanged demographic structure. If they live longer than expected, their saving will be inadequate to fund their longer life at the anticipated level of consumption. That is, their consumption will be lower than it would have been had they anticipated a higher probability of living into old age. Further, the bequests they leave to their children will be smaller, leaving this next generation with less income. Their children's income is further reduced by the rise in public pension taxes as a result of the increased longevity. Even one generation of unexpectedly long-lived agents 
can have permanent effects on the height of the growth path, if not on the long-run equilibrium rate of growth.

PROPOSITION 3: Economies with lower population growth rates, $n$, have higher growth rates if the sum of the education and family size effects is positive and exceeds the public pension effect.

With fewer children, education expenditures per child are higher. In addition, the bequest each of these children receives is higher. There are, however, two competing income effects. The family size effect is the standard Solow growth model effect of a lower population growth rate: higher per capita saving. This positive effect is countered by a negative income effect, the public pension effect. Public pension taxes are now higher to compensate for the smaller pool of taxpayers relative to retirees. If the education, bequest, and family size effects exceed the public pension effect, then economies with lower population growth rates will have higher equilibrium growth rates. If the tax effect dominates, a reduced population growth rate may lead to reductions in economic growth and social welfare, even without the added complication of longer lived elderly.

\section{Simulations: System Sustainability and Social Welfare}

In this section, we examine the effects of demographic changes, both anticipated and unanticipated, on growth and economic welfare. Social welfare in period $t$ is

$$
\begin{aligned}
W(t)= & \ln c_{t}(t)+v[p(t-1) /(1+n(t))] \ln c_{t-1}(t) \\
& +\delta[1+n(t+1)] \ln h_{t+1}(t) .
\end{aligned}
$$

Each generation's consumption at time $t$ is normalized by the size of the working-age generation at $t, N(t)$. The weight given to the young, $\delta$, is the same as the weight parents place on educating their children. We assume that $v>1$; the weight given to the elderly is in excess of their population weight. This allows for the initial optimality of a public pension program in an economy that is dynamically efficient. ${ }^{5}$ That $v$ exceeds unity implies that society as a whole puts greater value on the living standards of the elderly than on the living standards of the young or the middle-aged. That the old have greater influence than their population size would suggest is explored by Mulligan and Sala-i-Martin (1999). This social valuation could result from the voting habits and political activity of the elderly. Or, it could be a reflection of a negative external effect on the welfare of the middle aged and young of

\footnotetext{
${ }^{5} \mathrm{~A}$ public pension system may also be optimal in an economy with generation specific shocks. Such a system would require the possibility of transfers from workers to retirees and vice versa (Rangel and Zeckhauser 2001). Since existing systems do not allow for such transfers, we assume that social welfare considerations prevail.
} 
Table 1: Baseline parameter values

\begin{tabular}{lllllllc}
\hline Parameter & Canada & France & Germany & Italy & Japan & U.K. & U.S. \\
\hline$\alpha$ & 0.32 & 0.26 & 0.31 & 0.29 & 0.32 & 0.25 & 0.26 \\
$\xi$ & 0.292 & 0.601 & 0.520 & 0.539 & 0.196 & 0.175 & 0.385 \\
$\omega$ & 0.091 & 0.080 & 0.065 & 0.063 & 0.053 & 0.065 & 0.067 \\
$n$ & 0.581 & 0.241 & 0.177 & 0.164 & 0.260 & 0.114 & 0.450 \\
$p$ & 0.312 & 0.318 & 0.289 & 0.309 & 0.290 & 0.298 & 0.313 \\
$\begin{array}{l}\text { Annual growth } \\
\quad \text { rate of output }\end{array}$ & 0.0105 & 0.0177 & 0.0129 & 0.0227 & 0.0287 & 0.0167 & 0.0152 \\
$\quad$ per worker & & & & & & & \\
\hline
\end{tabular}

low living standards of the elderly. Thus, while the young individually cannot affect this, society as a whole can. All these provide a rationale for a public pension system in a dynamically efficient economy.

We begin by calibrating the model to match the recent growth experiences of each of the G7 economies. Each period is a generation, set equal to 25 years. The weight given by parents to the human capital development of their children, $\delta$, is 0.98 , for all countries, reflecting parental altruism. The additional weight placed on the elderly's consumption, $v$, is 3.0 (our results do not depend on the value of this parameter). This assures that the public pension system is initially optimal in all countries. ${ }^{6}$ There is no obvious best estimate for $\theta_{2}$, the elasticity of governmental expenditures on education. We initially assume $\theta_{2}=0.8$, high efficiency of governmental expenditures, but also consider $\theta_{2}=0.1$, low efficiency of governmental expenditures. For balanced growth $\theta_{1}+\theta_{2}=1$, so our choice of $\theta_{2}$ ties down the value of $\theta_{1}$.

The initial values for the country specific parameters in the model are given in Table $1 .{ }^{7}$ The share of physical capital, $\alpha$, for each country is from Bernanke and Gürkaynak (2001). The school tax rate, $\omega$, is the 1995 ratio of public expenditures on all levels of education to GDP (OECD 2001), adjusted for labor's share in output. The replacement rate, $\xi$, is the average public pension benefit as a percent of the average gross wage in 1995 (Chand and Jaeger 1996). France, Germany, and Italy have the most generous public pension systems with replacement rates above $50 \%$. Japan and the United Kingdom have the least generous systems with replacement rates below $20 \%$.

\footnotetext{
${ }^{6}$ Because saving, and hence economic growth, is higher in the absence of a pay-as-you-go public pension system, over time the optimality of such a system is eliminated unless the weight placed on the elderly is ever increasing.

${ }^{7}$ The equations for growth are set out in an appendix, available from the authors on request.
} 
Table 2: Demographic change

\begin{tabular}{lcrrrrrr}
\hline Parameter & Canada & France & Germany & Italy & Japan & U.K. & U.S. \\
\hline \multicolumn{2}{l}{ Working-Age Population: Growth Rate } \\
$n(j)$ & 0.581 & 0.241 & 0.177 & 0.164 & 0.260 & 0.114 & 0.450 \\
$n(j+1)$ & 0.235 & 0.040 & -0.054 & -0.040 & -0.137 & 0.098 & 0.233 \\
$n(j+2)$ & 0.012 & -0.077 & -0.192 & -0.242 & -0.242 & -0.063 & 0.131 \\
Longevity & & & & & & & \\
$p(j-1)$ & 0.312 & 0.318 & 0.289 & 0.309 & 0.290 & 0.298 & 0.313 \\
$p(j)$ & 0.373 & 0.376 & 0.358 & 0.369 & 0.428 & 0.347 & 0.350 \\
$p(j+1)$ & 0.452 & 0.459 & 0.465 & 0.509 & 0.519 & 0.430 & 0.431 \\
\hline
\end{tabular}

The growth rate of the working-age population, $n$, is given by the growth rate of the population aged 20 to 64 years between 1970 and $1995 .{ }^{8}$ Canada had the largest percentage increase in the working-age population while the United Kingdom had the smallest. The ratio of the population of retirees to workers in 1995 multiplied by the gross growth rate of the working-age population, $(1+n)$, gives the value for $p$.

Using these baseline parameter values and setting the growth rate of output per worker at its 1970-1995 average rate (Heston et al. 2002), allows us to determine the value of the constant, $A$, in the production function. We then introduce population aging and re-simulate the model, keeping all other parameters at their initial values.

Aging in our model is the result of two demographic factors: a decline in $n$ and an increase in $p$. Specifically, we assume life-expectancy rises beginning with the generation entering the workforce in period $j: p(j)>p(j-1)$ and continues for an additional period: $p(j+1)>p(j)$. Population growth slows beginning with the children of generation $j: n(j+1)<n(j)$ and continues with the next generation: $n(j+2)<n(j+1)$. These changes result in a reduction in the size of the working-age population relative to the retired population. The parameters corresponding to this demographic transition, given in Table 2, are based on the demographic projections for 2020 and 2045. By the second period, the population growth rate is negative in all countries except Canada and the United States. To prevent a collapse of the workingage population in our model, we assume that the working-age population remains constant following the two-period transition, as does longevity. As the population ages, the pension tax rate, $\tau$, rises to maintain the replacement rate as shown in Equation (11).

\footnotetext{
${ }^{8}$ Population data and projections for all countries are from the U.S. Bureau of the Census, International Database, Tables 004 and 094. Data are based on the July 17, 2003 update.
} 


\subsection{Perfect Foresight}

First, assume that agents have perfect foresight: they know the relevant value of $p$ for their generation: $\hat{p}(t)=p(t)$. The combined effect of increasing longevity and declining population growth rates results in a rise in saving per worker and human capital investment per child. These in turn increase output per worker as shown in Figure 1.

Increasing $p$ at $t=j$ has a positive effect on saving in period $j$, a longevity effect. In addition, generation $j$ 's human capital expenditures per child rise as $n(j+1)$ declines, a positive education effect. Both effects boost output per worker in period $j+1$.

In period $j+1$, longevity continues to rise and the population growth rate continues to decline. However, the positive longevity and education effects are now tempered by the negative bequest and public pension effects of the rise in $p(j)$ and the fall in $n(j+1)$. The boost in the growth rate of output per worker as a result of the change in demographics in the previous period, in combination with the longevity and education effects, ensure a further rise in the growth rate of output per worker in period $j+2$ in all countries.

In period $j+2$, longevity remains unchanged. The population of children in this period is now the same as the working-age population, $n(j+3)=0$. For Canada and the United States this is a decline in the population growth rate but for the other five countries the growth rate of the population rises, as $n(j+2)$ was negative. Thus, in the United States and Canada human capital
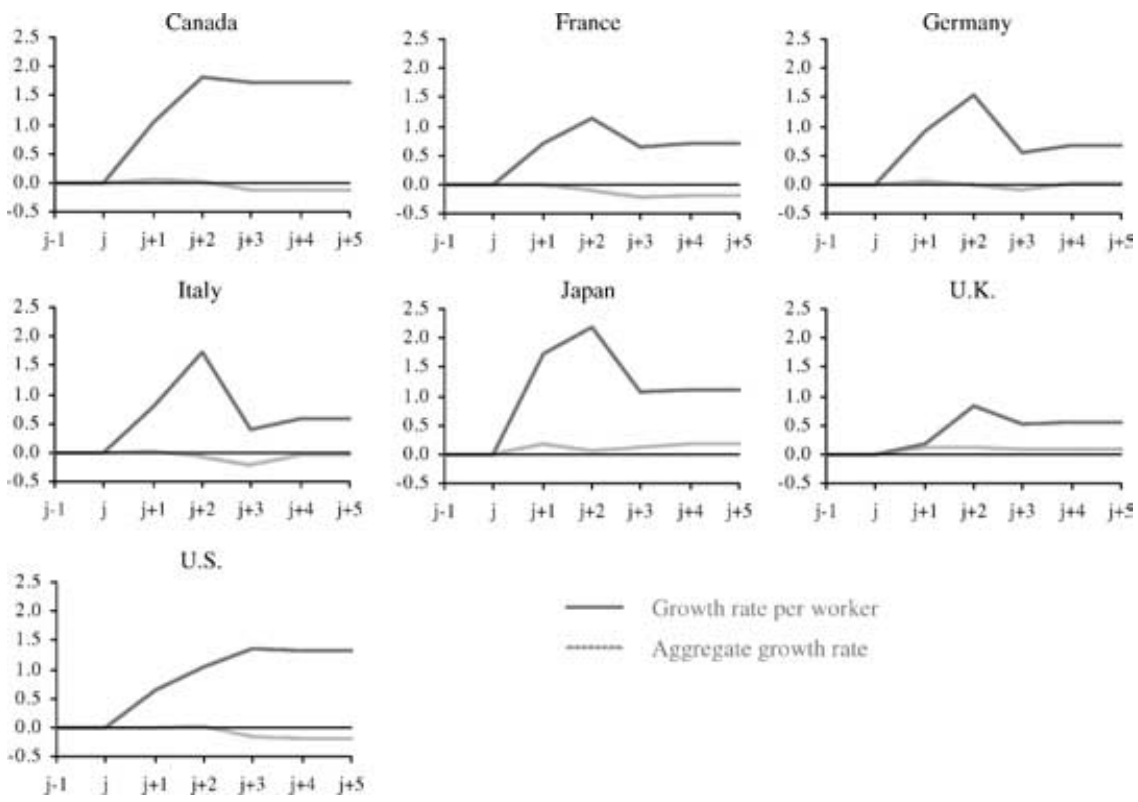

Growth rate per worker

Aggregate growth rate

Figure 1: Growth rate of output: $\lambda_{1}=1, \theta_{2}=0.8$, percentage point deviation from baseline 
expenditures per child continue to rise, while in the other five countries the rise in $n(j+3)$ has the opposite effect. In all countries the negative bequest and public pension effects continue. In Canada, the negative effects offset the education effect and the per worker growth rate falls slightly. Only in the United States does the growth rate in period $j+3$ rise.

In period $j+3$, there is a negative public pension effect in Canada and the United States as a result of the decline in $n(j+3)$, but a positive effect in the other five countries. Thus, the per worker growth rate of output falls slightly in period $j+4$ in the former two countries and rises in the other five. At this point the demographic transition is complete and the growth rate of output per worker is at its new, higher equilibrium.

A declining population growth rate will reduce the growth rate of aggregate output unless it is offset by a rise in the growth rate of output per worker. Only in Japan and the United Kingdom, is the rise in output per worker sufficient enough to produce a slight rise in the long-run growth rate of aggregate output, as illustrated in Figure 1. In these two countries, greater longevity, in combination with a low replacement rate, $\xi$, causes a rapid rise in saving to fund retirement, driving the rise in the growth rate of aggregate output.

The importance of the efficiency of government expenditures on education is illustrated by Figure 2, which shows the results of simulating the model assuming that $\theta_{2}=0.1$ for all countries. Lowering the estimate of $\theta_{2}$ results in a smaller rise in the growth rate of output per worker. In Germany and Italy,
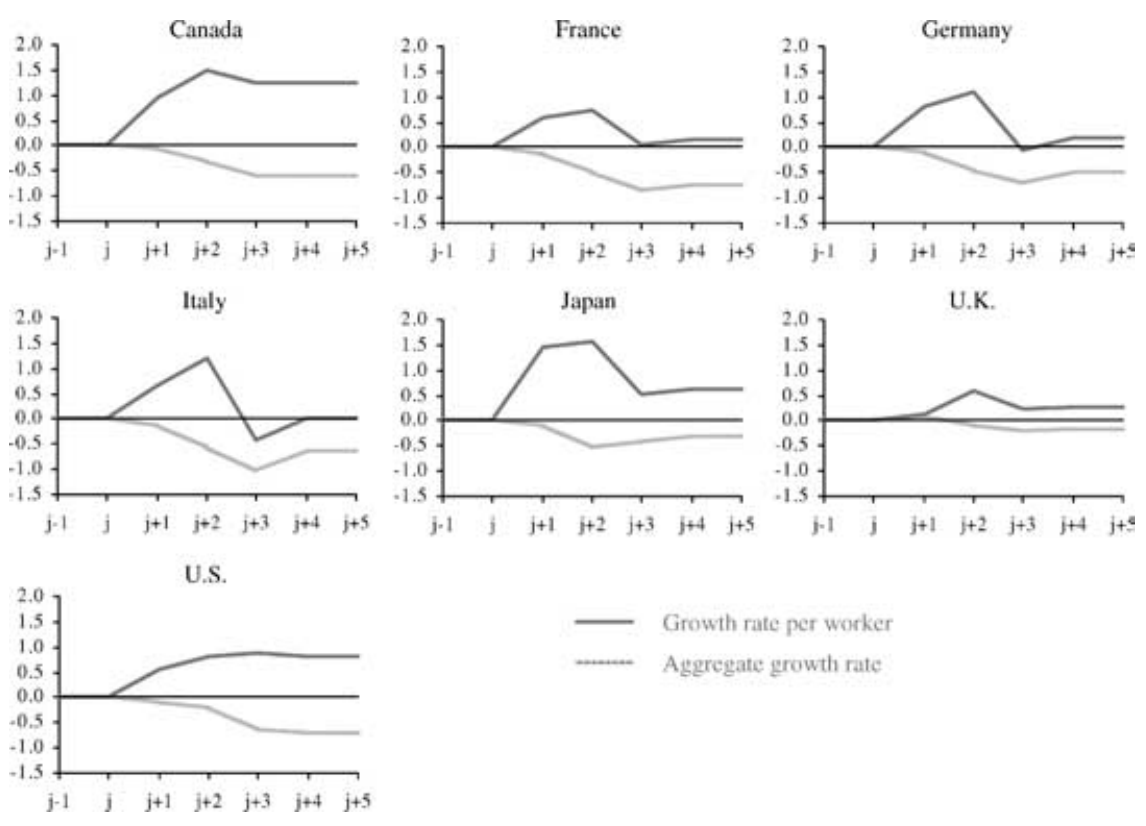

Figure 2: Growth rate of output: $\lambda_{1}=1, \theta_{2}=0.1$, percentage point deviation from baseline 
output per worker falls relative to the baseline during part of the transition. The lower $\theta_{2}$ produces a decline in aggregate output in all countries.

The demographic changes affect welfare through their effects on the weight given to each generation and on consumption. The increase in longevity raises the weight placed on the consumption of the retired generation and has a positive effect on welfare, as can be seen in Equation (18). The decline in the growth rate of the working-age population, first reduces the weight placed on human capital expenditures on children (a negative effect on welfare); eventually it also increases the weight placed on retirees, thus having an ambiguous effect on welfare. The positive effect of aging on the growth rate of output per worker increases consumption and has a positive effect on welfare. In the long run the positive effects dominate and welfare rises regardless of the choice of $\theta_{2}$, as shown in Figure 3 .

In all countries, except the United Kingdom, the initial (period $j$ ) negative effect of an increase in aging on welfare primarily results from the decrease in the population growth rate $n(j+1)$. Specifically, the middleaged increase their consumption as the lower population growth rate reduces parental expenditures on children, although expenditures per child rise. The human capital of each child, $h_{j+1}(j)$, rises, but the weight given to this generation in the welfare function falls as $n(j+1)$ decreases. The increase in consumption by the middle-aged is not large enough to offset this negative effect, and welfare in period $t=j$ falls. Over time, the increase in the growth rate
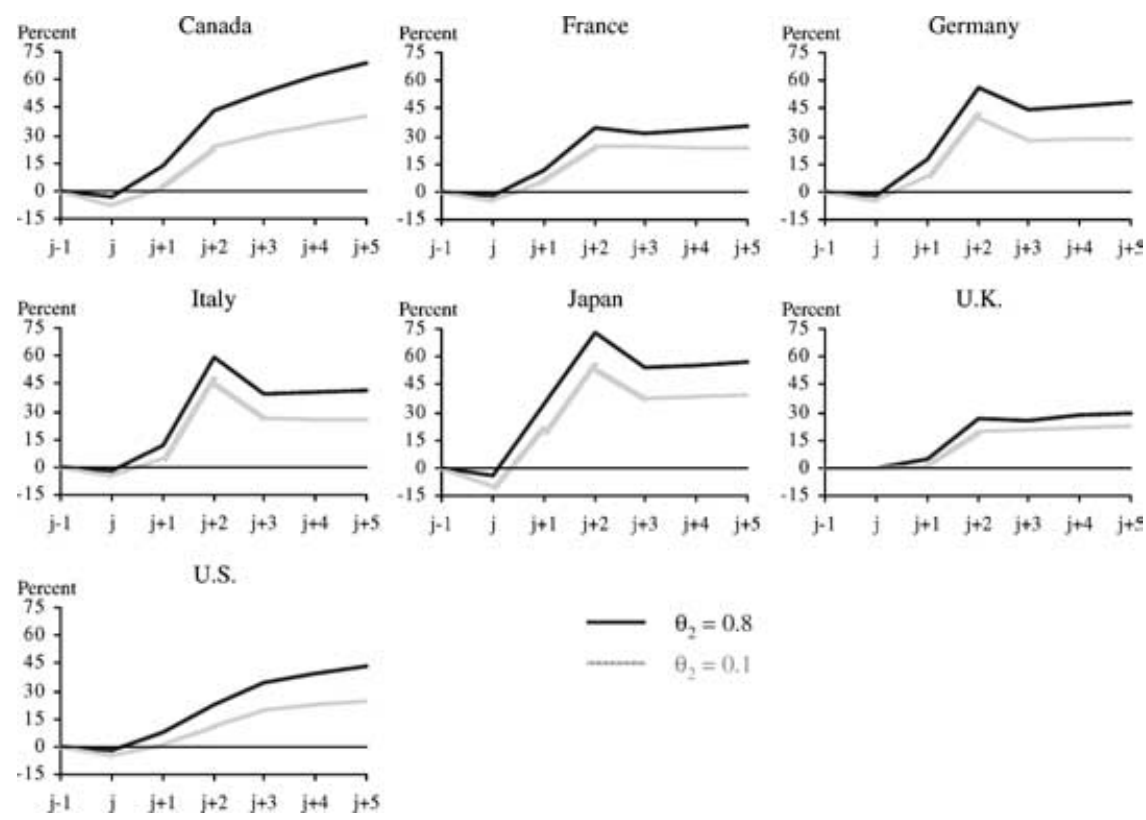

Figure 3: Welfare-perfect foresight, deviation from baseline 
Table 3: Expenditures on public pensions as a percent of output

\begin{tabular}{lccccccr}
\hline & Canada & France & Germany & Italy & Japan & U.K. & U.S. \\
\hline Predemographic transition & 3.9 & 11.4 & 8.8 & 10.2 & 3.1 & 3.5 & 6.2 \\
Postdemographic transition & 9.0 & 20.4 & 16.8 & 19.5 & 6.9 & 5.6 & 12.3 \\
\hline
\end{tabular}

of output per worker, resulting from increased physical and human capital per worker, raises consumption and welfare for all generations.

The decline in $n(j+1)$ is smallest in the United Kingdom. In this country the effect of the rise in $p(j)$ predominates. The low replacement rate induces a sharp rise in saving given a rise in expected longevity. In period $j$, consumption of the working-age population declines, as do parental expenditures per child. Human capital per child rises as an increase in government expenditures per child offsets the decline in parental expenditures. Nevertheless, the decline in the weight given to the young in the welfare function and the decline in the consumption of workers result in a small drop in welfare.

Perfectly anticipated aging raises output per worker and the welfare of future generations. Yet, an aging population results in substantial increases in public pension expenditures. Table 3 shows the share of pension expenditures in output prior to and following the demographic transition. These increases are similar to those estimated by Chand and Jaeger (1996) and Roseveare et al. (1996).

In our model, the systems remain economically viable, that is, contributions cover expenditures. This result may be affected by our assumption that labor supply is inelastic. If labor force participation rates are sensitive to the tax rate, $\tau$, then as the economy ages labor force participation rates fall as workers move, for example, into the informal sector. Under these circumstances, the systems in some countries may become insolvent.

\subsection{Adaptive (Myopic) Expectations}

We next conduct a number of simulations under alternative assumptions on individuals' expectations of their longevity and compare these with the perfect foresight results. To do so we assume that a working-age agent assumes his life expectancy is a convex combination of the actuarial forecast, $p(t)$, the life expectancy of his parents' generation, $p(t-1)$, and, possibly, the life expectancy of his grandparents' generation, $p(t-2) .{ }^{9}$ Thus, define

$$
\hat{p}(t)=\lambda_{1} p(t)+\lambda_{2} p(t-1)+\lambda_{3} p(t-3),
$$

where $\lambda_{1}, \lambda_{2}, \lambda_{3} \leq 1$ and $\lambda_{3}=1-\lambda_{1}-\lambda_{2}$.

We present results for three possible combinations of the $\lambda \mathrm{s}$. The first specification is $\lambda_{1}=\lambda_{2}=0.5$ : individuals place equal weight on the actuarial

${ }^{9}$ This simple formulation incorporates both myopia and learning. 
forecast and the experience of their parents' generation in assessing their own life expectancy. The second specification is $\lambda_{2}=1$. Individuals assess their probability of living into retirement as equivalent to that of their parents' generation. The third specification is $\lambda_{3}=1$. Individuals assess their probability of living into retirement as equivalent to that of their grandparents' generation. In all specifications, upon reaching retirement age, the true $p$ is revealed.

Myopia is harmful to economic growth, either on a per worker or aggregate basis. This is because as longevity increases and this increase is not taken into account, agents do not save adequately for their, unanticipated, longer lives. ${ }^{10}$ In the terminology of Proposition 2, the longevity effect disappears and only the negative income and bequest effects remain. ${ }^{11}$ Because, in our model, $p$ stabilizes after two periods, a myopic economy's growth rate converges to the perfect foresight long-run equilibrium value.

Welfare in the initial period, $t=j$, is higher under myopia than under perfect foresight, regardless of the efficiency of government expenditures on education. Figure 4 illustrates the results for $\theta_{2}=0.8$. The failure of workers to recognize an increase in longevity results in a shift in the allocation of income away from saving and toward current expenditures, relative to perfect foresight. Parental expenditures on children, as well as own consumption, rise. Since the initial generation of retirees is unaffected, welfare unambiguously rises. Although the rise in education expenditures in period $j$ has a beneficial effect on output in the next period, it cannot offset the negative effect of the decline in saving. The fall in output in $j+1$ and lower bequests relative to perfect foresight results in a decline in the working-age population's own consumption expenditures, and their expenditures on education. Also, the retired generation now reduces its consumption relative to the baseline due to the lack of adequate saving. Welfare falls and continues to fall, as shown in Figure 4, until the demographic transition is fully incorporated into individuals' saving behavior. Thereafter, the difference between welfare under myopia and perfect foresight narrows. The lower saving of the myopic generations leads to permanent decline in welfare relative to perfect foresight. The greater the degree of myopia, the greater is the loss in welfare. The extent to which myopia results in a reduction in welfare varies across countries. The greatest reduction in welfare occurs in Germany and the smallest reduction in the United States.

Myopia is often given as a reason for the existence of public pension systems. Yet, Feldstein (1985) showed that even if everyone in the economy is myopic, it still may be optimal to have no public pension system. A similar

\footnotetext{
${ }^{10}$ In our model, myopic individuals save for retirement, but their savings are inadequate given the increase in $p$. This is different from Feldstein (1985) and $\mathrm{Hu}$ (1996) in which myopic agents save nothing for retirement.

${ }^{11}$ These results would be the same if agents had rational expectations, but the longevity projections upon which they based their savings decisions proved to be too low.
} 

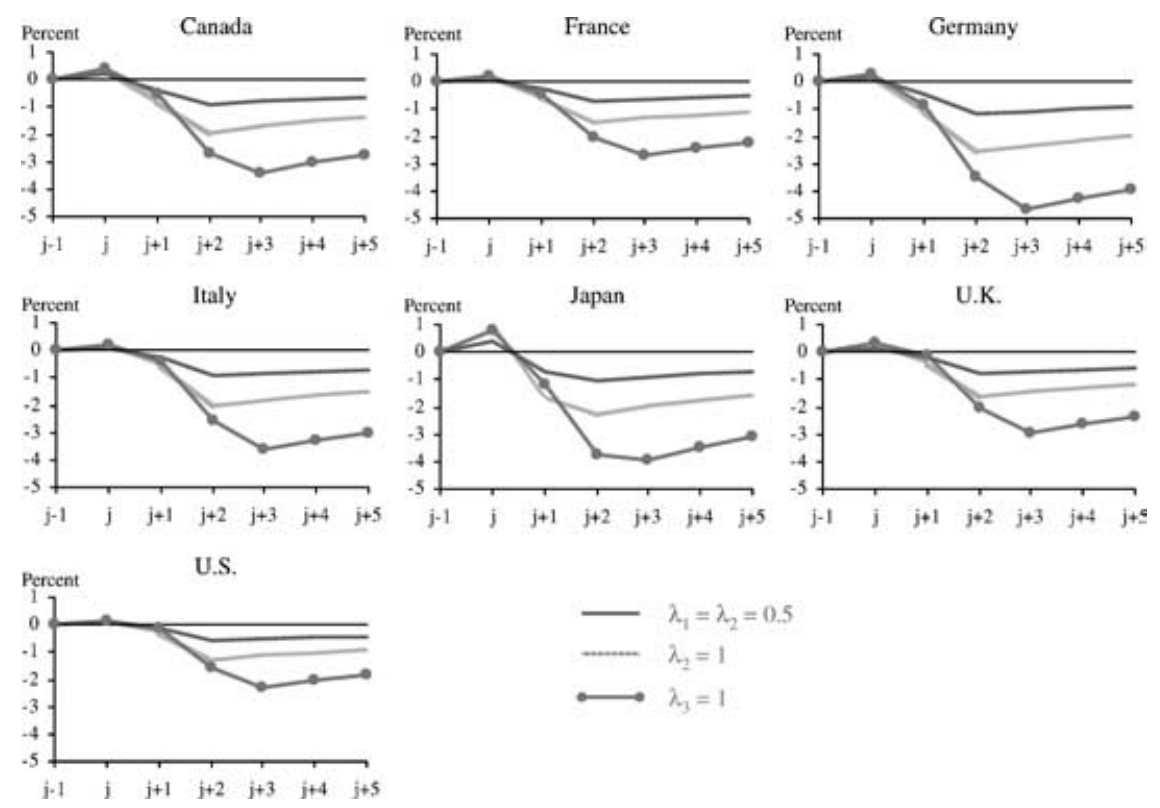

Figure 4: Welfare: $\theta_{2}=0.8$, deviation from perfect foresight

result follows from our model. As Figure 5 shows, the long-run deviation of welfare under myopia from perfect foresight is greater with a public pension system than without one. In addition, the short-run gain from myopia is higher in the absence of a public pension system. The decrease in saving of the myopic generations relative to perfect foresight is higher in the presence of a public pension system, while the increase in expenditures on one's children is lower. Both effects produce a lower growth rate, relative to perfect foresight, in an economy with a public pension system.

Japan is the country in our study that has already experienced substantial aging as a result of both a sharp drop in the growth rate of the workingage population and a rise in longevity. The growth rate of aggregate output in Japan has fallen when comparing the periods 1950-1975 and 1975-2000. This decline is consistent with either myopia or a low $\theta_{2}$. The growth rate of output per worker has also fallen in Japan, in contrast to the prediction of our model. This difference could be explained by the effect on growth of the rebuilding of the capital stock in the early postwar period.

\subsection{School Taxes}

Faced with a myopic population, is there any means available to a government to effect higher rates of saving? In our model, any forced saving plan, such as government-imposed mandatory pensions, would have the effect of reducing an individual's saving one-to-one (or more than one-to-one if the return on government pensions exceeds the return on an individual's own 

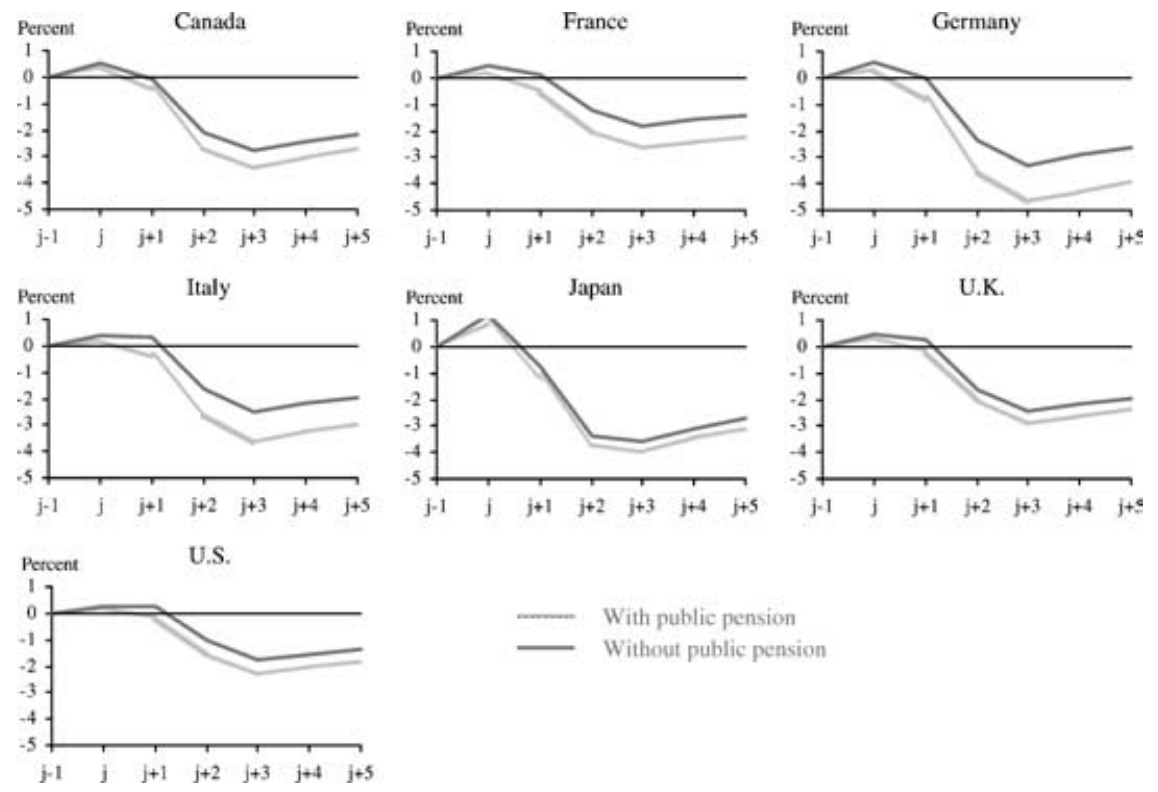

Figure 5: Welfare, deviation from perfect foresight, $\lambda_{3}=1, \theta_{2}=0.8$

saving). Thus, to achieve an increase in saving, government mandates would have to cause individuals to save in excess of their desired amount. While this may make them better off in an ex post sense, it will not make them better off ex ante.

Evidence from the Australian superannuation funds (the privatized portion of its pension system) provides support for the argument that governments are unable to force an increase in saving. In the first 5 years after contributions to the system became mandatory, the $\$ 110$ billion in accumulated assets were mostly offset by borrowings (The Economist, 1998).

If the government increases the school tax prior to the onset of aging, individuals are forced to save, in terms of their children's human capital, but do not view paying the tax as forced saving. This tax increase may generate improvements in growth and social welfare. ${ }^{12}$ The value of $\theta_{2}$ is crucial to these results. When $\omega$ is increased, income of the working-age population initially falls and so agents reduce their saving and their expenditures on human capital. If the efficiency of government expenditures on education is sufficiently high, then human capital and hence output will rise. Moreover, this rise in human capital expenditures will more than offset the decline in consumption of the working-age population, resulting from the higher tax, and hence welfare will rise. As Proposition 1 indicates, the lower is $\theta_{2}$ the

\footnotetext{
${ }^{12}$ If the rational expectations longevity projections proved too low, no such policy would be possible.
} 
lower is the optimal $\omega$. When $\theta_{2}=0.8$ all countries benefit from an increase in the school tax rate. When $\theta_{2}=0.1$ the optimal school tax rate is below the initial tax rate in Canada even prior to the demographic transition. Any increase in the tax rate lowers welfare. In France and Italy, welfare declines as the optimal school tax rate following the demographic transition is below the new tax rate.

If agents view parental and governmental expenditures on education as perfect substitutes then any attempt by the government to increase saving by raising the school tax rate will fail. Parents will reduce their expenditures on their children in line with the rise in government education expenditures.

\subsection{Trust Fund}

Another way to handle myopia is through the use of a trust fund. The value of a trust fund in period $t$ is the difference between revenues and expenditures of the public pension system and the gross return on any accumulated balances. The trust fund is equivalent to government savings:

$$
\begin{aligned}
s^{g}(t)= & \tau(t) w(t) h_{t}(t)-[p(t-1) \xi(t-1) /(1+n(t))] w(t) h_{t}(t) \\
& +[(1+\rho(t)) /(1+n(t))] s^{g}(t-1) .
\end{aligned}
$$

Now $\tau(t)=[p(t-1) \xi(t-1) /(1+n(t))]+\gamma(t)$, where $\gamma(t)$ is the increase in the public pension tax rate to support prefunding of benefits. Equation (20) then can be rewritten as

$$
s^{g}(t)=\gamma(t) w(t) h_{t}(t)+[(1+\rho(t)) /(1+n(t))] s^{g}(t-1) .
$$

The capital stock at time $t$ is now a combination of private saving, $s(t-$ $1)$, and public saving, $s^{g}(t-1)$. So the goods market clearing Equation (15) become $s(t-1)=[1+n(t)] k(t)-s^{g}(t-1)$.

The trust fund system can be set up in two ways. The first is to increase $\tau(t)$ (relative to the no action policy) by setting $\gamma(t)>0$ in the periods in which myopia results in an underestimation of longevity and lower $\tau$ in the next period(s) without changing $\xi$. For example, when $\lambda_{2}=1, \tau(j)$, and $\tau(j+1)$ rise while $\tau(j+2)$ and possibly $\tau(j+3)$ fall. The increase in $\tau$ reduces private saving both in terms of physical and human capital, as well as consumption expenditures of the affected working-age generations. The decline in private saving lowers consumption of the retired generation. All of these effects result in a reduction in welfare for the duration of the policy. Nevertheless, the physical capital stock rises, because government saving more than offsets the decline in private saving. As a result, welfare eventually rises once the trust fund is exhausted.

The second method is to increase both $\tau(t)$ and $\xi(t)$ for the myopic generations. When $\lambda_{2}=1, \tau(j)$ and $\tau(j+1)$ rise resulting in a two-generation trust fund. The replacement rates, $\xi(j)$ and $\xi(j+1)$, are chosen so that the trust fund is exhausted in period $j+1$. The increase in the tax rate and the 
rise in the replacement rate lower private saving by more than the increase in government saving. Total saving declines and future generations are made worse off. Because of this negative effect on saving, prefunding the public pension system lowers welfare in all periods.

\section{Conclusion}

Over a period of several generations, the proportion of retirees relative to workers is expected to rise as the population growth rate declines and longevity rises. In the face of this demographic transition, we assume that the government attempts to maintain the generosity of the public pension system by fixing the replacement rate at its preaging rate. Given this policy, we examine the effects of aging on growth and welfare under alternative assumptions on individuals' expectations of longevity.

If individuals fully anticipate increased longevity, and hence increase saving for retirement, then while aging generally reduces the growth rate of aggregate output, it need not reduce the growth rate of output per worker. If individuals have perfect foresight and prefer a longer life to a shorter life, aging does not reduce welfare in the long run. This prognosis is in stark contrast to Kotlikoff et al. (2001) and Gokhale and Kotlikoff (1999) who paint an unremittingly bleak portrait of the future given the demographic transition. Their results and ours could be reconciled if they were to revise saving behavior to account for myopia (under-saving given incorrect perception of longevity) and its correction via learning (perfect foresight) or amelioration via induced human capital investment (school taxes).

If individuals are myopic, then during the demographic transition the economic growth falls relative to perfect foresight. With myopic expectations the growth rate of the economy will, in the long run, match the perfect foresight growth rate. Welfare receives an initial boost as myopic individuals consume more and spend more on their children than the more frugal agents with perfect foresight. This gain is short-lived. Welfare is lower in all subsequent periods as a result of the lower savings of the myopic generations. These results are lower bounds since we have assumed that the supply of labor will not fall when social security taxes rise. For small changes in taxes this assumption may be reasonable, but this is not the case for the large changes in taxes forecast for many countries as they try to maintain their public pension systems in the face of population aging.

Given a myopic population, few policies are available to the government to offset the adverse growth and welfare effects. However, the government can raise the growth rate and welfare by inducing saving through human capital development, that is, raising the school tax rate. Such a policy, however, must be in place prior to the onset of aging. In addition, the success of such a policy depends on the efficiency of government expenditures on education. If government expenditures are not sufficiently productive, then raising school 
taxes will only exacerbate the effects of aging, lowering the output of the economy (relative to no increase), and hence lowering welfare.

While myopia in our model results from agents' failure to fully account for changing demographics, the effects on saving are similar to models in which consumers fail to adjust to changes in fiscal policies. Poterba (1988), for example, notes that while the U.S. public pension reforms enacted in 1983 reduced the present value of benefits for young workers, there is little evidence that these changes have had any effect on saving behavior. These results indicate that myopia rather than aging is primarily responsible for reducing growth and welfare when countries maintain their pay-as-you-go public pension systems as the population ages.

\section{References}

AUERBACH, A. J., L. J. KOTLIKOFF, R. P. HAGEMANN, and G. NICOLETTI (1989) The economic dynamics of an ageing population: The case of four OECD countries, OECD Economic Studies 12, 97-130.

BERNANKE, B. S., and R. S. GÜRKAYNAK (2001) Is growth exogenous? Taking Mankiw, Romer, and Weil Seriously, NBER Working Paper 8365.

CHAND, S. K., and A. JAEGER (1996) Aging populations and public pension schemes, IMF Occasional Paper 147.

CREMER, H., D. KESSLER, and P. PESTIEAU (1992) Intergenerational transfers within the family, European Economic Review 36, 1-16.

DOCQUIER, M., and P. MICHEL (1999) Education subsidies, social security and growth: The implications of a demographic shock, Scandinavian Journal of Economics 101, 425-440.

FELDSTEIN, M. (1985) The optimal level of social security benefits, The Quarterly Journal of Economics 100, 303-320.

GLOMM, G., and M. KAGANOVICH (2003) Distributional effects of public education in an economy with public pensions, International Economic Review 44, 917-937.

GOKHALE, J., and L. KOTLIKOFF (1999) Social security's treatment of postwar Americans: How bad can it get? Federal Reserve Bank of Cleveland Working Paper 9912.

HANUSHEK, E. A. (1992) The trade-off between child quantity and quality, Journal of Political Economy 100, 84-117.

HANUSHEK, E. A., and D. KIM (1995) Schooling, labor force quality an economic growth, NBER Working Paper 5399.

HESTON, A., R. SUMMERS, and B. ATEN (2002) Penn World Table Version 6.1, Center for International Comparisons at the University of Pennsylvania (CICUP).

HUBBARD, R. G., and K. L. JUDD (1987) Social security and individual welfare: Precautionary saving, borrowing constraints and the payroll tax, American Economic Review 77, 630-646. 
HU, S. (1996) Myopia and social security financing, Public Finance Quarterly 24, 319348.

HVIDING, K., and M. MÉRETTE (1998) Macroeconomic effects of pension reforms in the context of ageing populations: Overlapping generations model simulations for seven OECD countries, OECD Ageing Working Papers, AWP 1.3.

KAGANOVICH, M., and I. ZILCHA (1999) Education, social security, and growth, Journal of Public Economics 71, 289-309.

KOTLIKOFF, L., K. SMETTERS, and J. WALLISER (2001) Finding a way out of America's demographic dilemma, NBER Working Paper 8258.

MASSON, P. R., and R. W. TRYON (1990) Macroeconomic effects of projected aging in industrial countries, International Monetary Fund Staff Papers 37, 453-485.

MULLIGAN, C., and X. SALA-I-MARTIN (1999) Social security in theory and practice (ii): Efficiency theories, narrative theories and implications for reform, NBER Working Paper 7119.

OECD (2001) Education at a Glance: OECD Indicators, 2001 edition. Paris: OECD.

PECCHENINO, R., and P. POLLARD (2002) Dependent children and aged parents: Funding education and social security in an aging economy, Journal of Macroeconomics 24, 145-169.

POTERBA, J. (1988) Are consumers forward looking? Evidence from fiscal experiments, American Economic Review 78, 413-418.

RANGEL, A., and R. ZECKHAUSER (2001) Can market and voting institutions generate optimal intergenerational risk sharing? in Risk Aspects of Investment-Based Social Security Reform, J. Campbell and M. Feldstein, eds. Chicago: University of Chicago Press, 113-141.

ROSEVEARE, D., W. LEIBFRITZ, D. FORE, and E. WURZEL (1996) Ageing populations, pension systems and government budgets: Simulations for 20 OECD countries, OECD Economic Department Working Paper 168.

SAITO, J. (1998) Pension system reform leaves bitter legacy, Asahi News Service, July 8.

THE ECONOMIST (1998) Retiring the state pension, October 24-30.

TURNER, D., C. GIORNO, A. DE SERRES, A. VOURG'H, and P. RICHARDSON (1998) The macroeconomic implications of ageing in a global context, OECD Ageing Working Papers, AWP 1.2.

U.S. BUREAU OF THE CENSUS, International database. Available at $<$ http:/ /www. census.gov/ipc/www $\gg$. 